\title{
Place Cells and Silent Cells in the Hippocampus of Freely-Behaving Rats
}

\author{
L. T. Thompson ${ }^{1, a}$ and P. J. Best ${ }^{2, b}$ \\ 'Neuroscience Graduate Program and 2Department of Psychology, University of Virginia, Charlottesville, Virginia 22903
}

In the present study, nearly two-thirds of all hippocampal pyramidal units isolated under barbiturate anesthesia, which maximizes these cell's activity, were behaviorally silent. These "silent cells" showed no spontaneous firing activity in the awake, freely-behaving rat. Both reanesthetization and antidromic stimulation, however, activated these silent cells. More than $92 \%$ of the remaining spontaneously active hippocampal pyramidal cells recorded from freely-behaving rats were place cells; i.e., they exhibited spatially specific changes in firing activity in at least one environment. The firing rates of these place cells varied depending on the animal's location in this environment. Interestingly many of these place cells displayed low or no spontaneous activity and no spatial specificity in other, dissimilar environments; i.e., their lack of firing in some spatial environments mirrored the behavioral silence of the more numerous silent cells reported here. In complex information processing, such as the processing of spatial information by the hippocampus demonstrated here, neural silence may be as important a signal as neural activity.

The most frequent criterion used for identification of neurons in both intra- and extracellular recording studies is spontaneous activity. If a cell is not active, its physiological identification as a neuron is questionable. In any given electrode track through a brain region, however, more neurons can be visualized proximal to the electrode than show spontaneous activity (Fox and Ranck, 1975, 1981; Dykes and Lamour, 1988). In some cases, unit signals are impossible to isolate from one another, because of their small amplitude and the close packing of other neurons in their immediate vicinity. In other cases, however, when during a recording session only one or a handful of spikes are recorded over a long period of time from a previously isolated neuron, it is difficult to verify the signal as that of a reliable unit. These infrequently active cells are usually not included in samples used for functional analysis. In the present study, how-

\footnotetext{
Received Aug. 26, 1988; revised Jan. 5, 1989; accepted Jan. 6, 1989.

This work was supported in part by NSF Grant BNS-81-19030 and by a UVA Presidential Fellowship. We wish to thank Dr. Eric Lothman for advice and assistance on chronic stimulation, and numcrous UVA undergraduates for technical assistance. Submitted in partial fulfillment of the requirements for the Ph.D. in the Neuroscience Program (L.T.T.).

Correspondence should be addressed to L. T. Thompson, Department of Cell Biology and Anatomy, Northwestern University Medical School, 303 E. Chicago Avenue, Chicago, IL 60611.

a Present address: Department of Cell Biology and Anatomy, Northwestern University Medical School, Chicago, IL 60611.

' Present address: Department of Psychology, University of New Orleans, New Orleans, LA 70148.

Copyright (C) 1989 Society for Neuroscience $0270-6474 / 89 / 072382-09 \$ 02.00 / 0$
}

ever, these inactive or "silent" cells were systematically examined and included in our analyses of hippocampal singleunit activity.

For over 10 years, researchers working in this laboratory have noted a recurrent problem while investigating the parameters controlling the activity of hippocampal complex-spike cells in freely-behaving rats. Many units, isolated in anesthetized rats, appeared to be lost when the animals recovered from anesthesia and exhibited no spontaneous firing during subsequent testing of other active units in the waking animal. Other units fired at a rate so low that they might be mistaken for recording artifacts and were typically excluded from analysis. However, these lost or inactive cells reappeared and showed robust activity during periods when the rats were in slow-wave sleep or when the rats were reanesthetized in the course of making marking lesions to verify electrode placements (Olmstead and Best, 1974; Thompson et al., 1985). Anecdotal data indicated that a significant number of cells were involved. The present study examined the proportions of these behaviorally silent cells in the hippocampus relative to those demonstrating a well-described behavioral correlate, place field activity.

O'Keefe and Dostrovsky (1971) first reported that many hippocampal complex-spike cells fire at high rates in specific places within an environment. Subsequent studies (O'Keefe, 1976; O'Keefe and Conway, 1978; Olton et al., 1978; Miller and Best, 1980; Hill and Best, 1981; Best and Hill, 1982; Best and Ranck, 1982; Buzsáki et al., 1983; McNaughton et al., 1983; Best and Thompson, 1984b; Muller et al., 1987) have replicated and extended this finding. Most complex-spike cells recorded in the awake intact rat reliably differentiate among spatial locations within a given environment. These cells fire rapidly in their place field and have low spontaneous firing rates outside this field. Although these and other studies have examined a number of parameters that affect place field activity, the factors that make a hippocampal neuron a place cell remain unclear.

At this point, it is appropriate to define some terms introduced here and used throughout the remainder of this study. Spontaneous activity refers to any single-unit activity of a neuron in the awake rat. Evoked activity refers to single-unit activity elicited by an experimental variable, such as electrical stimulation, location within a place field, or pharmacological manipulation. Since waking rats always occupy a spatial location, some component of the total observed spontaneous activity may be attributable to activity evoked by spatial stimuli (this attribution may be tested, as described in Materials and Methods). A silent cell is one that has no spontaneous activity and evoked activity only in response to sleep/waking changes in state or to electrical or pharmacological stimuli. (Cells whose activity cannot be 
evoked by any of these manipulations are also, in fact, silent but are excluded from analysis here due to our lack of ability to detect them). Place cells in awake rats vary their firing rates in specified and circumscribed places within at least one environment. As will be seen, cells having place fields in one environment can appear to be silent in other environments, yet will not be classed as silent cells according to the terms defined here. Background activity is the spontaneous firing activity of a single unit in an awake rat that occurs outside the place field of the unit.

In a review of studies of hippocampal units, O'Keefe (1979) stated that place cells "constitute the majority of the cells in the hippocampus," basing his assertion on data obtained from units isolated in waking rats. In their studies mapping the anatomical distribution of theta and complex-spike cells in the freely-behaving rat, however, Fox and Ranck $(1975,1981)$ noted that the firing rate of many complex-spike cells in the awake rat is so low that random samples of spontaneous unit activity may fail to detect the presence of these cells. The recording protocols of most place cell studies (and indeed of most neurobehavioral studies), which rely on isolation of units in awake animals, tend to exclude inactive or infrequently firing cells.

O'Keefe and Conway (1978) first reported that many of the hippocampal cells that have place fields in one environment do not have place fields in other test environments; unfortunately, the characteristics of the activity (or lack thereof) of these cells in their non-place field environments were not described. In later studies, Kubie and Ranck $(1982,1983)$ reported that many complex-spikc cclls that show place field activity in onc cnvironment are actually silent in other environments; i.e., their spontaneous firing rates approach zero. Our own work has also reported cells that were silent in one environment yet showed spontaneous firing and place field activity when in other environments (Thompson et al., 1985; Thompson and Best, 1986). In other words, recordings from hippocampal units whose presence is previously undetected in the awake animal becomes possible after the introduction of the rats to a new test environment.

Use of a single behavioral test and/or a single testing.environment tends to increase the proportion of unsampled cells or to artificially strengthen the hypothesis that most pyramidal cells are place cells, rather than the more appropriate hypothesis that most spontaneously active pyramidal cells are place cells. The present study was undertaken in the interest of more accurately assessing the general population of hippocampal pyramidal neurons, rather than only those units that are particularly active. Since many hippocampal units are silent within a given environment, the investigative methods had to distinguish between the presence of units that are always silent within a given environment and loss of unit activity due to electrode movement or neuronal death.

For the present study, it was decided to isolate units under conditions in which the activity of hippocampal pyramidal units was likely to be maximal to ensure the most reliable sample possible for these neurons. Previous work indicates that pyramidal cell activity in rats tends to increase during slow-wave sleep (Mays and Best, 1973, 1975; Ranck, 1973; Best and Best, 1976; Buzsáki et al., 1983; Suzuki and Smith, 1985). At low doses, GABAergic agonists (including pentobarbital) decrease theta cell activity and the theta rhythm (Leung and Vanderwolf, 1980; Leung, 1984a; McNaughton et al., 1986; Misgeld and Frotscher, 1986), and may reduce postsynaptic inhibition of pyramidal cell activity (Leung and Vanderwolf, 1980; Leung, 1984b; Leung and Yim, 1986), while at higher doses barbiturates increase hippocampal inhibition (Laurent et al., 1983; Proctor et al., 1986). Although increased activity by all observed pyramidal cells does not necessarily equate to activity by nondetectable cells, it is a reasonable first approximation. To ensure that unit isolation could be maintained across experimental conditions (see Best and Thompson, 1984a; Thompson and Best, 1988), unit activity was required during reanesthetization to verify continued isolation. Units were tested in more than one environment, to test the variance in spontaneous activity that occurred across environments. Finally, a sample of silent cells was electrically activated in freely-behaving rats to demonstrate that these were indeed behaviorally silent neurons, and not a simple recording artifact.

\section{Materials and Methods}

Behavioral training and testing. Fifty-seven male hooded rats of the Charles River strain $(290-350 \mathrm{gm})$ were trained for several weeks to explore different environments, which were later used to test for place field activity. The first environment was a 6 -arm radial maze $(1.45 \mathrm{~m}$ in diameter, elevated $0.7 \mathrm{~m}$ from the floor) centered in a dimly lit, blackcurtained Farraday cage $(2 \times 3 \times 2.3 \mathrm{~m})$. The second environment used was a cylindrical opaque-walled drum $(0.7 \mathrm{~m}$ in diameter, $0.7 \mathrm{~m}$ deep $)$ placed atop the maze, with a white stripe on one wall serving as a polarizing visual stimulus. The third testing environment was a rectangular opaque-walled conditioning box with a grid floor $(0.5 \times 0.5 \times$ $0.5 \mathrm{~m}$ ) placed atop the maze. A video camera used to record the rat's spatial behavior was hung from the ceiling, centered above the maze.

The rats were food-deprived to $80 \%$ of their ad libitum weight, familiarized with the 3 test environments, and trained to run on the maze using a win-shift paradigm (Olton and Samuelson, 1976). A small piece of "Froot Loops" cereal was placed at the end of each maze arm as a reinforcer, and rats were placed in the center of the maze at the beginning of each set of 6 trials. Incorrect choices were scored whenever a rat reentered an arm previously visited within the set of trials. The rats were trained until they reached a behavioral criterion of 6 out of 6 correct choices on 2 out of 3 daily sets of trials for 5 consecutive days. In subscquent trials, the win-shift paradigm was modified, with each arm baited at random intervals to maintain rapid exploration of al arms of the maze. Well-trained rats then typically completed 10 or more circuits of the maze in less than 10 min during behavioral testing. On each day of maze training and testing, each rat was also placed in both the drum and the conditioning chamber for $45 \mathrm{~min}$. Exploration of the drum was encouraged by throwing in 4 or 5 pieces of "Froot Loops" at random intervals, which scattered and were retrieved by the rat from various locations. A water bottle was occasionally made available at varying locations around the wall of the rectangular box to encourage active exploration of this environment. The sequence of presentation of the 3 environments was randomly varied across days.

Instrumentation and single-unit recording. Driveable bundles of ten $32 \mu \mathrm{m}$ nichrome microwire electrodes (Kubie, 1984) were chronically implanted in the dorsal hippocampus of the rats under barbiturate anesthesia (UVA Animal Research Committee Protocol \#1163-06-87). Several days after surgery, the rats were anesthetized as described below and the electrode assemblies were advanced until one or more hippocampal complex-spike cells were isolated extracellularly. Conservative criterion for single-unit isolation were used: the peak-to-peak amplitude of the unitary signal had to exceed that of all other signals (except decremental spikes within a complex-spike burst) on the electrode by at least a factor of $4: 1$ for inclusion in the study; i.e., individual signals from electrodes with multiunit activity were not included in the statistical analyses. Only the first spike of complex-spike bursts was digitized and used for compilation of rate data. The peak amplitudes of the negative spike of all unitary activity and of all decremental complexspikes had to vary by less than 5\% within and across sessions (including all ancsthetized periods) for inclusion in the study.

Complex-spike units were differentiated from the other major behavioral class of hippocampal units, theta cells, by frequently published criteria (see Ranck, 1973; Fox and Ranck, 1975, 1981), including waveform and rate of activity. Complex-spike activity was also considered, 
but not used as a rigid criterion, since the proportion of complex-spike bursts to single spike firings varied considerably between neurons, and even for the same neuron within 45 min sessions.

Unit activity in the behaving rat was amplified by source-follower FETs attached to the chronic headblock and differentially recorded against an adjacent hippocampal electrode in the same bundle and/or an indifferent cortical electrode. Unit signals were amplified with Grass P15 AC preamplifiers (gain $\times 10$; bandpass $300-3.0 \mathrm{kHz}$ ) and BAK MDA-3 AC differential amplifiers (gain $\times 1000$; bandpass $500-5.0 \mathrm{kHz}$ ), and displayed on an oscilloscope. Single-unit activity was digitized using time/amplitude window discriminators.

In some rats, the hippocampal EEG was monitored through adjacent hippocampal electrodes on which poorly isolated hippocampal unit activity was present (bandpass $0.1-50 \mathrm{~Hz}$ ) to allow detection of slow-wave activity, which was monitored on an oscilloscope or chart recorder. While most rats were immediately returned to the center of the maze when exploratory behavior ceased, to encourage further exploration, 7 rats were allowed to remain undisturbed so that immobility and sleeprelated EEG and neuronal activity could also be occasionally monitored. Periods of more than $10 \mathrm{sec}$ duration in which the sustained EEG frequency was less than $6 \mathrm{~Hz}$ and the rat was immobile were scored as slow-wave sleep.

Bipolar stimulating electrodes $(100 \mu \mathrm{m}$ Teflon-insulated stainless steel wire) were implanted in the fimbria-fornix of 5 rats for electrical activation of population and single-unit activity. Single-pulse square wave stimuli at $0.05-0.10 \mathrm{~Hz}, 0.25 \mathrm{msec}$ duration, $0.5-2.5 \mathrm{~V}$ intensity were used.

Unit activity and place field measurements. A video camera centered over the test environments allowed recording of a rat's location on video tape, while unit activity was recorded on the audio channels. A small DC lamp was mounted atop the electrode assembly, and an imaging device digitized the spatial coordinates of the light continuously (Best and Thompson, 1984b; Muller et al., 1987). Testing sessions for each unit lasted at least $45 \mathrm{~min} / \mathrm{d}$. If no spontaneous unit activity occurred in the awake, freely-behaving rat, it was verified as behavioral silence of the unit, rather than loss of unit isolation, by reanesthetizing the rat and examining unit activity. If unit activity could not be induced by reanesthetization, forcing the conclusion that unit activity was lost, unit data was discarded, and the electrode was again advanced in $30 \mu \mathrm{m}$ steps until additional complex-spike units were isolated or the experiment was terminated. Small electrolytic marking lesions were used to localize the electrode tip at termination, and unit recording sites were calculated from records of electrode advancement relative to the lesion site observed in Nissl-stained sections.

Place field activity was analyzed by computer as follows. The Cartesian coordinates of the animal's spatial location were mapped each time a unit fired. Independently and simultaneously, the coordinates of all locations visited by a rat within a session were mapped. These sets of coordinates for each environment were divided into square grids, 50 $\mathrm{mm}$ on a side. Grids in which at least $5 \mathrm{sec}$ of behavior were not observed were excluded from analysis. The mean rate of activity of each neuron was calculated within these grids by dividing the number of spikes fired in each grid by the amount of time spent in each grid. Firing rates within a grid greater than 3 SD above the mean firing rate for the entire environment were used to define the boundaries of place fields. This is a more conservative measure of the boundaries of a place field than is used by some researchers, but is quite reliable statistically (Olton et al., 1978; Hill and Best, 1981).

Testing protocols. 1 . The electrode assembly was advanced, and unit activity was isolated and recorded from all rats while they were anesthetized with the barbiturate pentobarbital $(25 \mathrm{mg} / \mathrm{kg}$, i.p.). Unit activity was again recorded during subsequent reanesthetization following behavioral testing. Only units demonstrating similar physiological characteristics during both periods of anesthetization were included in this study.

2. Unit activity was recorded while rats foraged on the radial maze and in one or more of the nonmaze testing environments. Food or water reinforcement was available at irregular intervals during testing to encourage active exploration of the environments. Both mean spontaneous firing rates and place-related firing rates were quantified and compared among environments.

3. Fimbria-fornix stimulation $(0.4 \mathrm{msec}$ duration pulses, $2-20 \mathrm{~V}$ intensity) was used in 5 rats to evoke single-unit responses. Fimbria-fornix activation of units (previously isolated under anesthesia) in the awake freely-behaving rat was used to confirm that loss of an isolated unit was not the cause of behavioral silence in a test environment. Units were initially driven in the ancsthetized rat, to determine stimulation parameters necessary to obtain 1:1 following of the stimulus by unit activity. No collision tests were attempted. If no spontaneous unit activity was present in the awake rat, the same stimulation parameters were again used to evoke unit activity while the rat actively explored the maze, and the waveforms of the evoked unit activity were compared with that obtained under anesthesia to ensure that the same unit was being observed in both sets of conditions.

Analyses of variance for repeated measures were used to test for differences in firing rates between anesthetized and awake conditions, while 1-way analyses of variance were used to test for differences in firing rates between the 2 observed behavioral categories of units (place and silent cells) tested under the same conditions. A $\chi^{2}$ test was used to compare the observed and predicted frequency of place field activity occurring in any given pair of environments.

\section{Results}

A total of 273 dorsal CA1 hippocampal complex-spike cells were isolated under anesthesia and followed during subsequent behavioral testing and reanesthetization. Figure 1 shows the principal electrode placement sites in dorsal $\mathrm{CA} 1$ of the rat hippocampus from which unit activity was recorded. Recording sites for all complex-spike cells reported were in or within 50 $\mu \mathrm{m}$ of stratum pyramidale of CA1 of the hippocampus. Ninetynine out of 273 units ( $36.8 \%$ of all complex-spike cells isolated) showed reliable place field activity in certain places within at least one of the test environments and exhibited low spontaneous firing rates outside these place fields. These units are referred to as place cells. Units that had place field activity in one environment were often silent or had low spontaneous rates of activity in other environments but are not termed silent cells (see Discussion below). Finally, 174 out of 273 units (63.2\% of all complex-spike cells isolated under anesthesia) showed no spontaneous firing within any of the spatial test environments, but their evoked activity was otherwise indistinguishable from place cells. Since these units were spontaneously inactive, they are referred to as silent cells.

The rates of spontaneous unit activity under various conditions and of activity evoked by barbiturate anesthesia were tested to determine if and when silent cells differed from place cells in their physiological activity. Table 1 lists the mean firing rates for all cells tested in the various conditions.

The mean firing rates of individual units under anesthesia were tested to determine whether silent cells differed from place cells in the initial evoked activity condition used for unit isolation. A significant difference in activity under anesthesia could have resulted in disparate numbers of units isolated from each group. If, for instance, a class of cells had a slower rate of firing under anesthesia, the probability that those cells would be detected and isolated would be decreased relative to a class of cells having a higher firing rate. However, the mean firing rates for all place cells and all silent cells in the anesthetized state were not significantly different from one another $(F=2.02, p>0.10)$. Further, both place cells and silent cells were indistinguishable from one another during slow-wave sleep; silent cells were active at the same rate as place cells in this condition. Based upon a sample of 23 place cells and 44 silent cells, mean firing rates for both silent cells and place cells did not differ from one another during slow-wave sleep $(F=1.27, p>0.25)$. Interestingly, the mean rates of activity during slow-wave sleep did not differ from the mean rates observed under anesthesia for silent cells $(F=1.52, p>0.25)$ or for place cells $(F=1.40, p>0.25)$, indicating that the activity evoked by barbiturate anesthesia was 


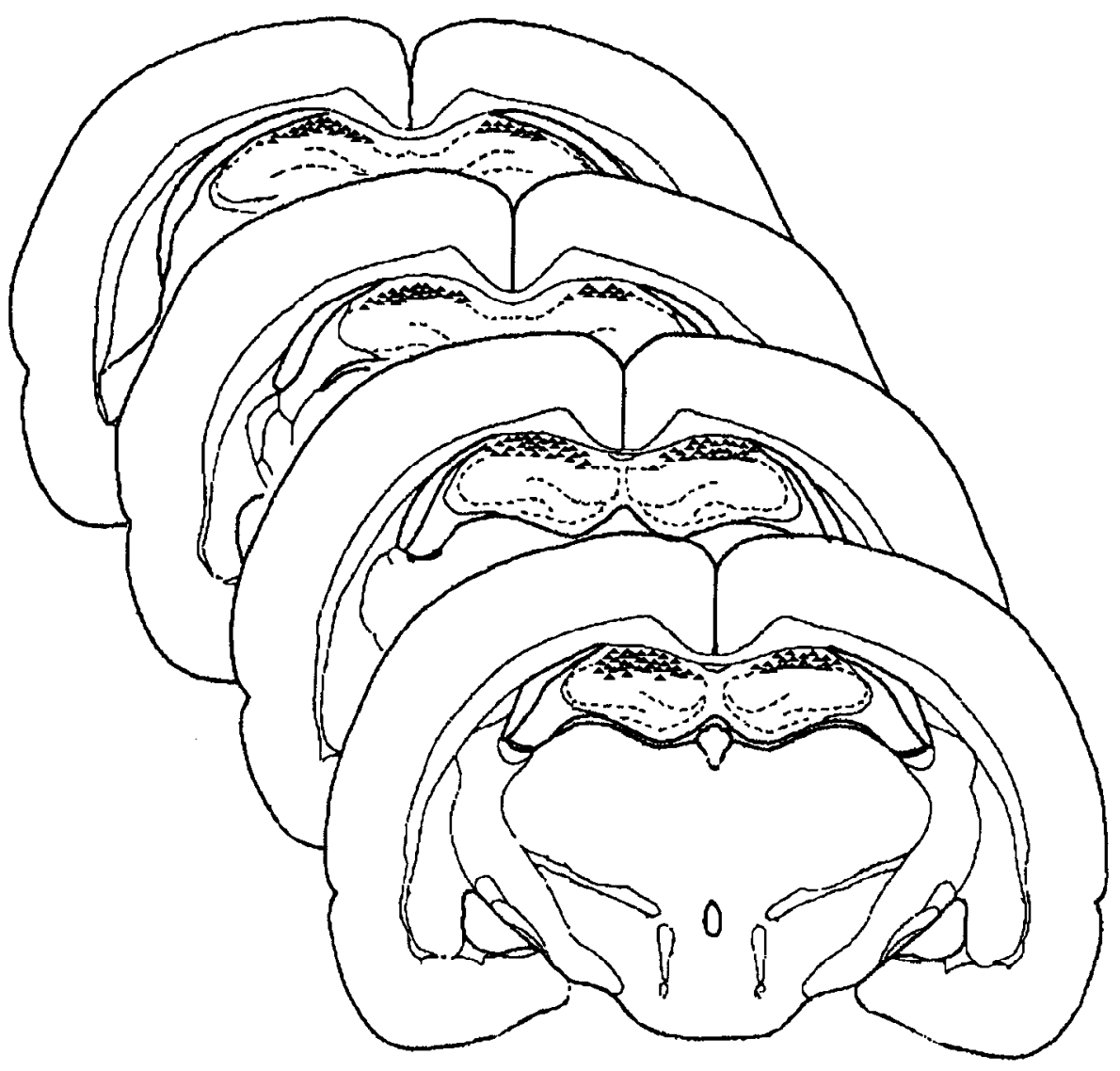

Figure 1. Location of dorsal hippocampal electrode sitcs from which unit activity was recorded, identified by filled triangles. The number of sites shown does not match the number of units reported since considerable overlap in electrode placements occurred between animals. similar to that occurring spontaneously in the sleeping but not the waking state.

Silent cells exhibited unmeasurably low or no spontaneous activity in the awake rat: their firing rate was as close to zero as can be accurately assessed with current techniques. Out of 174 silent cells observed during exploration of one or more spatial environments for periods of at least $45 \mathrm{~min}$ in awake rats, only 11 showed any spike activity whatsoever (see Fig. $2 E$ ). Of these 11 , only 2 fired more than 3 spikes/hr, with one firing a burst of 5 spikes in a single complex-spike burst, and one firing 7 single spikes at average interspike intervals of $9 \mathrm{~min}$. No statistical test to compare silent cell waking "activity" to anesthetized evoked activity was required.

Figure 2 shows the firing activity or lack thereof of a dorsal hippocampal stratum pyramidale silent cell recorded extracellularly under a number of different conditions. Under barbiturate anesthesia $(A)$ and during slow-wave sleep $(B)$, unit activity was characteristic of hippocampal complex-spike cell firing. In the awake, freely-behaving rat, however, firing activity approached a rate of zero $(C-E)$. During subsequent reanesthetization $(F)$, unit activity again was similar to that originally seen when the unit was first isolated.

Table 1. Mean firing rates (in $\mathrm{Hz} \pm$ SEM) of hippocampal pyramidal cells tested under a number of conditions

\begin{tabular}{llc} 
State & Place cells & Silent cells \\
\hline Anesthetized & $1.42 \pm 1.15$ & $1.29 \pm 0.99$ \\
Slow-wave sleep & $1.30 \pm 0.94$ & $1.38 \pm 1.05$ \\
Awake & & \\
$\quad$ Across all 3 environments & $0.82 \pm 1.07$ & $<0.0003^{a}$ \\
In environments with no place fields & $0.13 \pm 1.60$ & - \\
Across entire environment with place field & $1.12 \pm 0.47$ & - \\
$\quad$ Background (outside of place field) & $0.91 \pm 0.33$ & - \\
In On place field & $8.79 \pm 0.92$ & - \\
In Off place field & $0.09 \pm 0.10$ & -
\end{tabular}

Although place cells and silent cells were indistinguishable from one another on the basis of their firing activity under barbiturate anesthesia or during slow-wave sleep, they were readily differentiated in the awake, freely-behaving rat.

"Average of less than 1 spike event in 45 min of testing. 


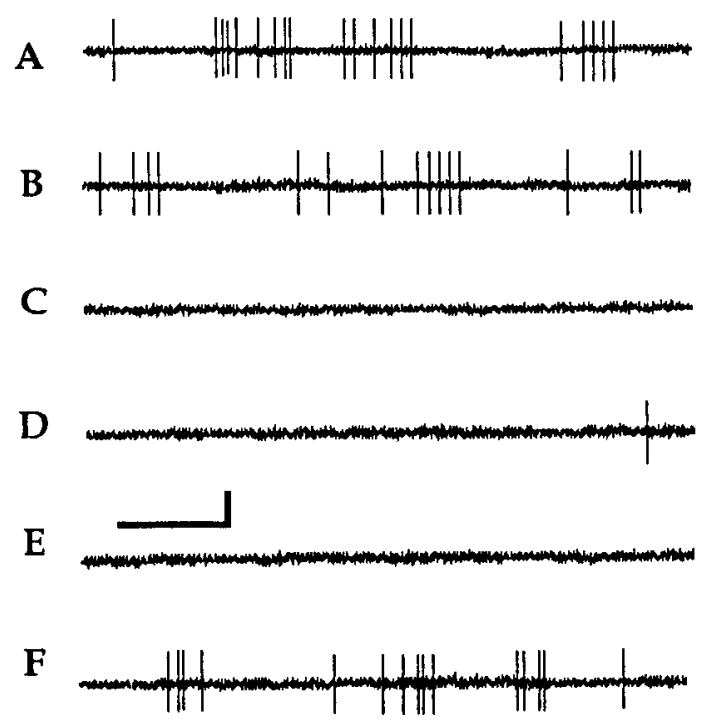

Figure 2. Linographic extracellular records of a single CA1 pyramidal unit under various experimental conditions. $A$, The rat was anesthetized with $25 \mathrm{mg} / \mathrm{kg}$ pentobarbital, i.p. The unit fired characteristic bursts of single spikes, with occasional complex-spike activity. $B$, The rat was in slow-wave sleep. The unit again fired characteristic bursts of single spikes. $C$ and $D$, The rat was actively exploring an open radial-maze $(C)$ and an enclosed drum $(D)$. The unit exhibited no spontaneous activity. $E$, The rat was quiet and awake, sitting immobile or grooming on the central platform of the radial-arm maze. The unit spontaneously fired a single spike during a $20 \mathrm{~min}$ period of nonexploration. $F$, The rat was reanesthetized with $25 \mathrm{mg} / \mathrm{kg}$ of pentobarbital, i.p. The unit again fired characteristic bursts of single spikes. Calibration bars, $1 \mathrm{sec}$, $200 \mu \mathrm{V}$.

We found that $63.2 \%$ of all complex-spike cells isolated in anesthetized rats showed no spontaneous firing during quiet awakefulness or during testing in any of the spatial environments. These cells' silence persisted during each trial of behavioral testing (in 7 cases, silent cells were followed over periods in excess of $6 \mathrm{~d}$, while other place cells in the same animal were observed; in 61 cases, silence was observed in the same environments on 2 or more sessions). All such behaviorally silent cells again showed reliable unit activity during subsequent reanesthetization. Paired $t$ tests indicated no significant differences in firing rates for individual silent cells between the 2 anesthetization periods $(t=0.59, d f=173, p>0.20)$, which strengthens the case that the same cells were observed across the entire experiment.

A better case, however, can be made that the same units were followed across all experimental conditions. Eight silent cells were driven by fimbria-fornix stimulation in both the awake and anesthetized rat (see Fig. 3). One-to-one following was observed at moderate rates of stimulation $(0.01-0.4 \mathrm{~Hz})$. Stimulus evoked firing had no effect on subsequent spontaneous activity during awake bchavioral testing, as all units continued to remain silent in all environments tested except during stimulus evoked activity. The amplitudes and waveforms of stimulus evoked responses were similar to those that were evoked by barbiturate anesthesia or that occurred during slow-wave sleep, and the evoked amplitudes and waveforms were constant whether stimulation occurred in the awake or the anesthetized rat. Two silent cells were followed for more than $4 \mathrm{~d}$ in this manner, with stimulus-evoked activity remaining invariant across the entire interval, while spontaneous activity of the cells remained zero in the awake rat. When the rats were reanesthetized, all silent
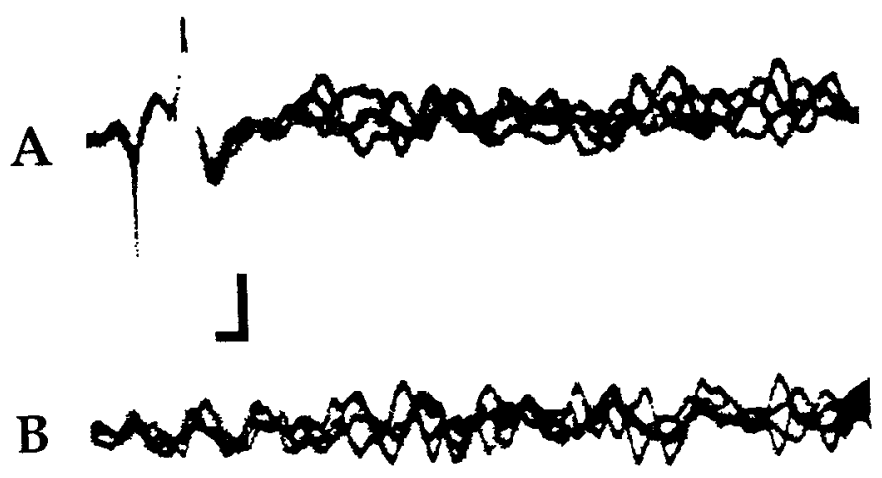

Figure 3. A, Five successive traces from a hippocampal pyramidal cell activated by fimbria-fornix stimulation (single pulse, $0.25 \mathrm{msec}$ duration) in an awake, freely-behaving rat exploring a radial-arm maze. The unit fired with a fixed latency of $2.2 \mathrm{msec}$ after each stimulus. $B$, Five successive traces from the same unit, without stimulation, in the awake, freely-behaving rat. No unit activity is detectable. Calibration bar, 1 $\mathrm{msec}, 100 \mu \mathrm{V}$.

cells again showed evoked activity that was statistically identical to that seen during the initial period of unit isolation.

Place cells in the awake rats exhibited spontaneous activity in one or more spatial environment. Further tests revealed that place cells show lower spontaneous firing rates (averaged across all environments) when the rat is awake than when under anesthesia $(F=5.10, p<0.02)$. Most place cells had a place field in only one environment and were silent or had lower spontaneous firing rates in other environments, and $75.7 \%$ of place cells had no place field in at least one of the environments tested. Only $14.2 \%$ of place cells had place fields in 2 or more environments, and only $1.4 \%$ had place fields in all environments tested.

Figure 4 shows computer-generated maps of the unit activity of a cell demonstrating simple place field activity. On these place field maps, the dark boxes indicate firing rates more than $3 \mathrm{SD}$ above the grand mean rate, while the smaller dots indicate areas that were visited but did not have this place field activity. As in this example, most place cells active on the maze had fields that did not include entire arms of the maze. Some cells had fields in discrete locations in the center of the maze and did not fire in other locations at the center or on the arms of the maze.

All place cells reliably altered their firing rates each time the rat entered a specific place within an environment, which was designated as the cell's place field. As in previous studies (Olton et al., 1978; Miller and Best, 1980; Hill and Best, 1981), both $O n$ and $O f f$ place field activity was identified. On fields were characterized by an increase in firing (more than 3 SDs above the mean firing rate across the entire environment) within a place, while $O f f$ fields were characterized by a decrease in firing (more than 3 SDs below the mean across the environment) within a place. Several units demonstrated mixed activity, having both $O n$ and $O f f$ fields within the same environment.

On place fields were more common than Off or mixed field types in all environments, but the more spatially complex environment (the open radial-arm maze) had a larger proportion of $O f f$ or mixed types than the simpler spatial environments (see Fig. 5). Off fields were most commonly observed for cells with moderate to high spontaneous rates of activity, due to the statistical requirement that firing be more than 3 SDs below the mean firing rate for the entire environment.

No discernible relationship was found between the location 


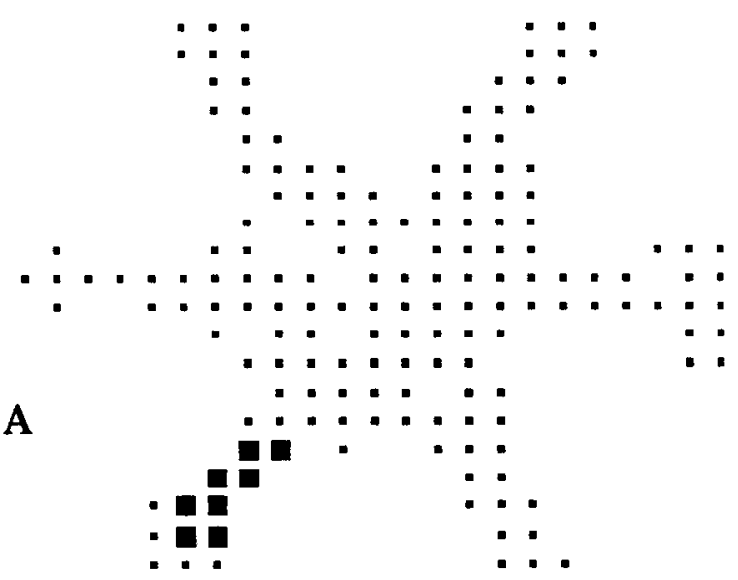

B

of any cell's field in one environment and its field (if it was not silent) in a different environment. For example, the unit whose $O n$ fields on the radial-arm maze and the enclosed drum are seen in Figure 4 also had an Off field in the enclosed box which covered the southwest corner of the box (not shown). The location of the place field of an individual cell was stable within and across sessions, although the location of place fields varied between cells recorded simultaneously or sequentially on the same electrode (Best and Thompson, 1984b; Thompson and Best, 1986; L. T. Thompson and P. J. Best, unpublished observations).

Out of 551 sessions in which single units were tested in single environments, 424 yielded no spontaneous unit activity and thus no place field activity (i.e., in $76 \%$ of all observations, hippocampal pyramidal cells had no spontaneous unit activity in the awake, freely-behaving rat). Twenty-two of these cases involved cells that demonstrated spontaneous activity as well as place field activity in other environments, indicating that in some environments, identified place cells were indistinguishable from presumed silent cells. For only 9 of the remaining 108 cells ( $8.3 \%$ of all spontaneously active cells) was the variability in unit activity insufficient to meet the criterion used to define place field activity in at least one environment. In other words,

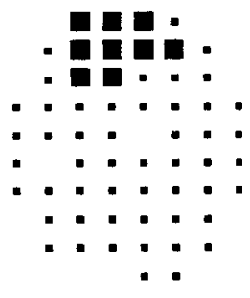

Figure 4. $A$, The place field of a CA pyramidal unit, mapped on a radialarm maze. Place fields (defined by unit firing more than $3 \mathrm{SD}$ above the grand mean firing rate) are indicated by solid squares, and background activity in all other areas visited by small dots. $B$, The place field of the same unit, mapped in an enclosed drum. Note that the locations of the 2 fields in the 2 environments are unrelated. Most units tested in different environments had no place field in at least one of them.

$92 \%$ of all hippocampal pyramidal cells observed in freely-behaving rats that were spontaneously active in at least one environment were also identified as place cells in at least one environment. Units were most likely to show place field activity on the radial-arm maze, the most spatially complex environment. Out of 255 cells tested on the radial-arm maze, $86(33.7 \%)$ had place fields on the maze; only 9 cells (3.5\% of those tested) had place fields in other environments but none on the maze. Of 212 cells tested in the enclosed drum, only $20(9.4 \%)$ had place fields in the drum; $39(18.4 \%)$ had place fields elsewhere, but no place fields in the drum. Of 81 cells tested in the enclosed box, $18(22.2 \%)$ had place ficlds in the box; $21(25.9 \%)$ had place fields elsewhere but not in the box.

The background firing activity of place cells varied from environment to environment, with some cells resembling silent cells in some environments, i.e., they had rates of spike activity $<0.0003 \mathrm{~Hz}(<1$ spike/session) when observed in these environments. Over $60 \%$ of place cells had spontaneous background rates in environments in which they had no place fields that were less than half their background firing rates in environments in which they had place fields. Figure 6 shows a comparison of mean firing rates of identified place cells in non-place field and in place field-containing environments. An apparent rightward

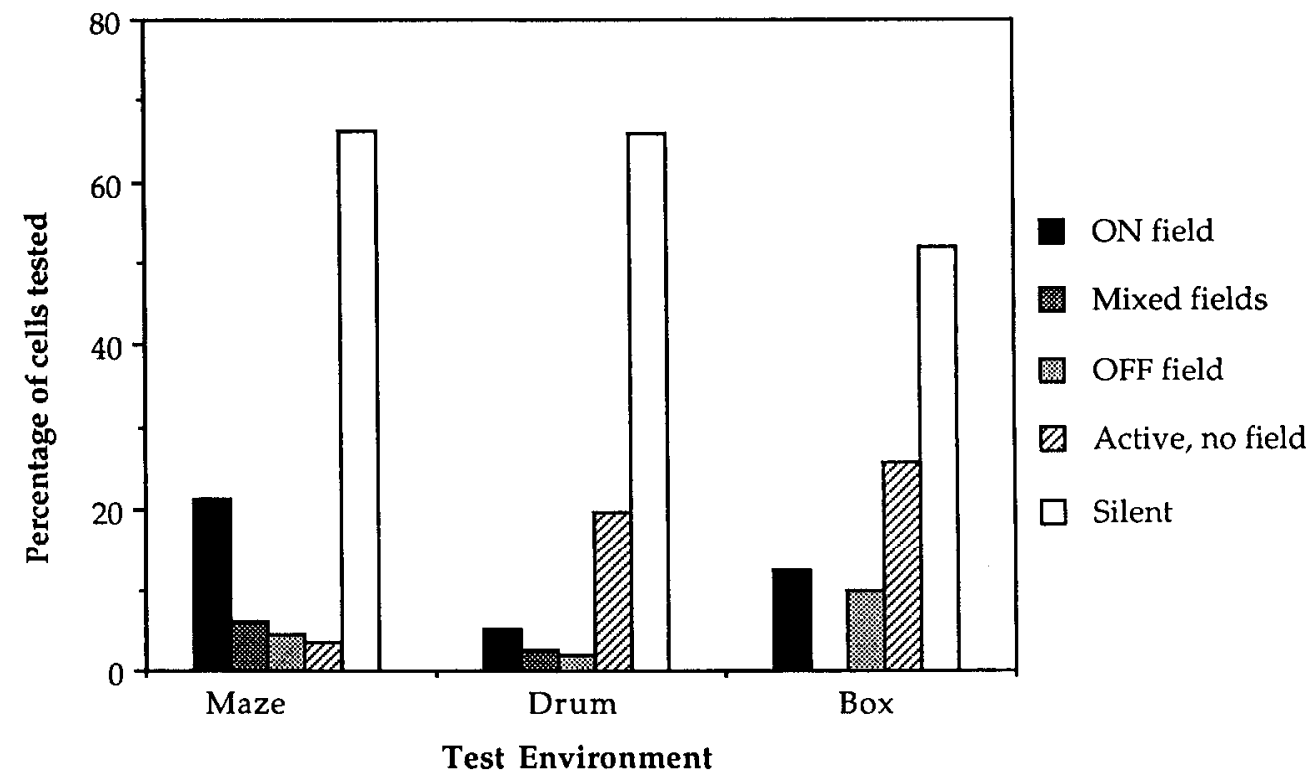

Figure 5. Proportions and types of place fields and proportions of non-place field activity observed during testing in 3 different spatial environments. Silent cells never exhibited place field activity in any of the environments tested. Identified place cells frequently had no place field activity in some environments. More units had place fields when tested on the radial-arm maze than in either of the simpler environments. 
Figure 6. The mean firing rates (in $\mathrm{Hz}$, plotted on a $\log$ scale) of hippocampal place cells when rats were exploring nonplace field environments (i.e., ones not containing place fields, open circles) and environments containing place fields. Both the spontaneous firing rates (i.e., the rate across the entire environment, including the place field, filled triangles) rate, excluding place fields, squares) were higher in environments containing place fields than was the spontaneous firing rate of the same cells in environments rightward shift in the mean firing freplace field activity is found. and the background firing rates (i.e., the in which they had no place fields. A quency occurs in environments in which

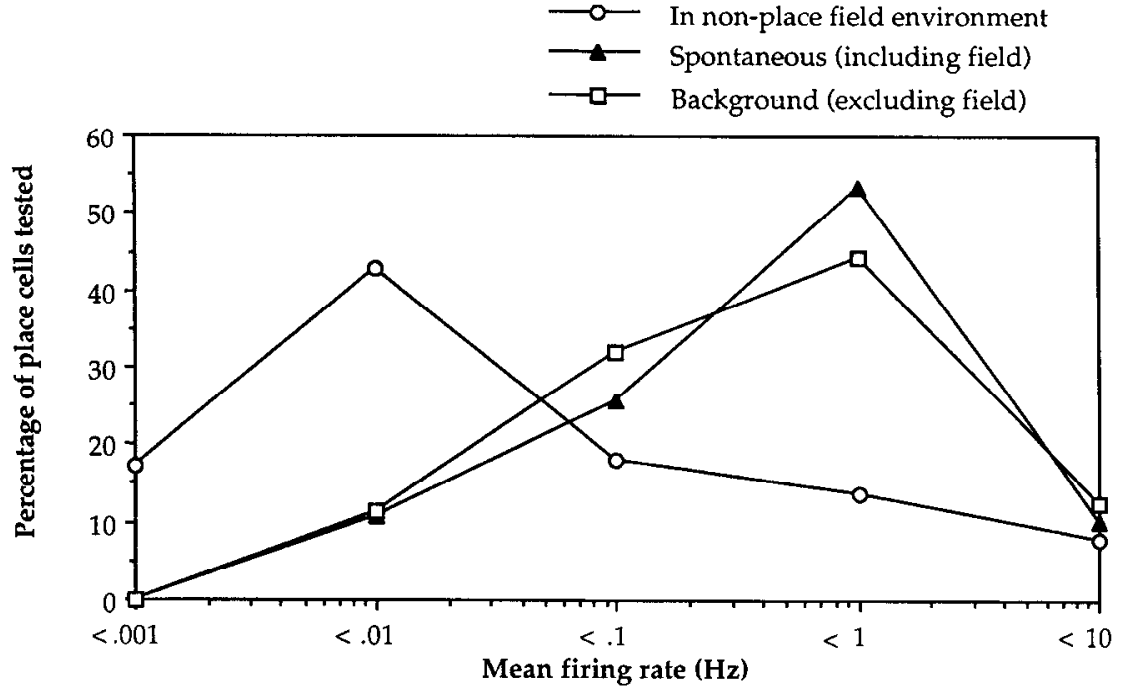

shift in background firing frequency is seen in pyramidal cell activity in environments containing place fields, which occurs both outside the place field, and includes the more extreme rightward shift represented by $O n$ place fields.

A binomial distribution was calculated, based on the number of place cells exhibiting place field activity in given pairs of environments, to estimate the incidence of place fields that would be predicted in testing in any given pair of environments. For this statistic, it was assumed that each environment tested was independent of all other environments tested (based on the unrelated fields observed in different environments) and that all hippocampal pyramidal cells were potential place cells. The binomial took the form

$$
\begin{gathered}
p_{\text {field in any given 2 environments }}=\left[p_{m} \times p_{d}\right]+\left[p_{m} \times P_{b}\right]+\left[p_{d} \times P_{b}\right] \\
-\left[p_{m} \times p_{d} \times P_{b}\right]
\end{gathered}
$$

where $m, d$, and $b$ denote the maze, drum, and box environments. The observed probability of a cell having a place field in 2 environments $(p=0.142)$ was compared with the predicted probability $(p=0.110)$. Pearson's $\chi^{2}$ test for goodness of fit indicated no significant difference in the observed and predicted incidence of place fields in any 2 given environments $\left(\chi^{2}=0.29\right.$, $p>0.5$ ), which leads us to conclude that testing in additional environments would reveal additional place field activity, some of which would be detected from cells currently classed as silent cells.

\section{Discussion}

The majority (over 63\%) of the hippocampal complex-spike cells isolated and tested in the present study did not display place field activity. In fact, they were behaviorally silent during exploration of spatial environments. This finding is, at first glance, in marked contrast to O'Keefe's (1979) assertion that most, if not all, hippocampal neurons are place cells. Three independent methods were used to ensure that the sample of hippocampal complex-spike units included in the present study did not artificially exclude specific subpopulations of neurons.

In 5 rats, unit activity was antidromically driven, by means of chronic stimulating electrodes implanted in fiber pathways, to verify continued isolation of silent units in freely-behaving rats. Additionally, by testing for place field activity in multiple environments, estimates of the proportion of known place cells likely to have place fields in different environments were obtained. This series of experimental protocols permitted more accurate estimates of the proportion of hippocampal pyramidal cells displaying place field activity to be made than was previously possible.

Another method used to sample unit activity from a larger proportion of the hippocampal neuronal population than is usually examined in studies of place cells was to repeatedly anesthetize the rat. As noted earlier, low doses of barbiturate anesthesia enhance the firing rate of hippocampal pyramidal neurons (Olmstead and Best, 1974), without requiring extensive invasive procedures in chronic animals, and thus increase the likelihood that a given neuron will be identified and isolated during the passage of an electrode through its vicinity. This increase in complex-spike cell unit activity is inversely correlated with a decrease in hippocampal theta activity (Leung and Vanderwolf, 1980; Leung, 1984a), which many researchers would regard as evidence of a decrease in recurrent inhibitory modulation of hippocampal pyramidal activity. Hippocampal theta activity is also low during slow-wave sleep, when large numbers of pyramidal cells are active (Ranck, 1973; Best and Best, 1976), which offers an alternate physiological control for the disinhibition observed under barbiturate anesthesia. Unfortunately, experimental isolation of single units with chronic microdrive assemblies requires physical manipulation of the assemblies and precluded the possibility of locating units while the rats were in slow-wave sleep in the present study.

Additional physiological evidence of complex-spike cell disinhibition in normal, freely-behaving rats has been reported in studies of hippocampal sharp waves, formerly termed large irregular activity (LIA). Buzsáki (1986) reported difficulty in attempts at isolating hippocampal single units during large irregular sharp wave activity in the rat hippocampus, when normal feed-forward inhibition briefly ceases and large numbers of formerly silent cells display synchronous activity throughout the hippocampal circuit. During such events, many silent hippocampal pyramidal cells were reported to be physiologically active. Atropinc, which selectively blocks theta unit activity, was reported to increase sharp wave synchrony. We noted sharp wave activity in our EEG and unit records most frequently during arousal from barbiturate anesthesia and during periods 
of alert immobility, when successive waves of unit activation were matched by EEG spike activity. To avoid skewed estimates of unit firing rates due to variance in time spent in inactivity, our behavioral testing protocols excluded periods in which awake immobility occurred and encouraged continued exploratory behavior. During most of our observations of exploratory behavior, sharp-wave activity was absent. This is likely due to the placement of our recording electrodes, generally centered within the pyramidal cell layer, at or near the lowest amplitude point for CA1 sharp waves (Buzsáki, 1986), and also to the regular theta rhythm that was observed in the hippocampal EEG. The fact that silent cells were active during slow-wave sleep (which shares many physiological characteristics with sharp-wave activity) in the present study is suggestive that active inhibitory mechanisms may regulate the observed silence of many hippocampal pyramidal cells.

Theta cells have been proposed as the active mediators of pyramidal cell inhibition (Feder and Ranck, 1973; Ranck, 1973; Fox and Ranck, 1975, 1981). The specific relationship between the firing of theta cells and of complex-spike cells in rats has not been well characterized. A preliminary study has reported that the specificity of place cell firing is sharpened during movement-related hippocampal theta activity and that out-of-field firing by place cells is greatly reduced under these conditions (Kubie et al., 1985b). Theta cell activity is highest during active movement and exploration (Ranck, 1973; Sinclair et al., 1982), when many pyramidal cells in the present study were silent. Buzsáki et al. (1983) reported that atropine treatment selectively blocks firing of some hippocampal theta cells, while increasing the activity of some complex-spike cells. The data presented here from anesthetized rats of increased pyramidal cell firing extends earlier reports of barbiturate-induced decreases in hippocampal theta activity (Leung and Vanderwolf, 1980). Converging lines of evidence suggest that active inhibition of pyramidal cell activity by theta cells may underlie many of the neurobehavioral correlates observed to date, including the silent cells reported here.

Decreased firing by hippocampal pyramidal cells has been shown during REM sleep and upon arousal from slow-wave sleep (Mays and Best, 1975; Best and Best, 1976). The present study has shown similar patterns of decreased firing upon arousal from anesthesia, for both place cells and silent cells. Theta cells are active during behavioral exploration and are inactive under barbiturate anesthesia or during slow-wave sleep, when pyramidal neurons are most active. These relationships are consistent with the possibility that theta cells act to inhibit pyramidal cells. In our hands, silent cells showed essentially no spontaneous activity in any of the environments tested. Place cells, on the other hand, showed extreme spatial specificity of firing, with a pronounced rightward shift in firing frequency observed in environments in which place field activity occurs. One simple explanation for these findings is that outside of the place, place cell firing is inhibited. The degree of inhibition varies from complete (in which case silent cells, with no spatial specificity, are observed), through partial (in which firing activity is low and spatially nonspecific) to none (within the place field). This inhibition could serve to enhance the processing of multisensory spatial information that presumably occurs within the hippocampus.

In many cases, the function of specific classes of neurons such as projection cells, local circuit neurons, and others, and of particular regions (such as identification of cortical area 17 as primary visual cortex) are inferred from the firing correlates of spontaneously active neurons (Hubel and Wiesel, 1962, 1977). This method of investigation has been met with wide acceptance within the scientific community. In fact, O'Keefe (O'Keefe and Nadel, 1978; O'Keefe, 1979) postulated a global mapping function for the hippocampus based upon such an argument. As the present study indicates, however, the spontaneous activity of the neurons in a region under a controlled set of conditions may not be representative of all neuronal activity in the region over the course of a wider selection of behaviors. Other studies have recently shown that a large number of neurons in other brain areas may be silent under a given set of experimental conditions (Foutz et al., 1987; Dykes and Lamour, 1988). In the present experiment, the goodness of fit of the observed and predicted incidence of place field activity in different environments supports O'Keefe's (1979) assertion that the majority of hippocampal pyramidal cells are place cells, even though in most cases most of the cells observed are behaviorally silent. (This does not rule out other functional correlates of hippocampal pyramidal cell activity, but only asserts that these cells are capable of place field activity.) Assuming an infinite number of test environments (or a smaller subset, more likely to be encountered over the lifetime of the organism), the likelihood that any given cell is engaged in place-related activity in a given environment is not large. As observed, in most environments most hippocampal cells are not actively signaling (via changes in firing activity) the animal's location in space. This silence may have as great an importance in the processing of spatial information as the increases in activity most commonly described as place field activity.

The fact that place cells and silent cells have the same electrophysiological characteristics under anesthesia, that place cells are frequently virtually silent in many places outside their place fields, and that silent cells are inactive in the awake animal leads to the conclusion that tight inhibitory control of pyramidal cell activity occurs within the hippocampus. Behaviorally silent cells may be place cells that have been tested under conditions where the place stimuli are inadequate to overcome this inhibition. The silence of silent cells may not be a negative finding, but rather a further indication of the precision of the processing of spatial information by the hippocampus.

\section{References}

Best, M. R., and P. J. Best (1976) The effects of state of consciousness and latent inhibition on hippocampal unit activity in the rat during conditioning. Exp. Neurol. 51: 78-109.

Best, P. J., and A. J. Hill (1982) Visual and auditory cues support place field activity of hippocampal units in the rat. Adv. Behav. Biol. 26: 99-117.

Best, P. J., and J. B. Ranck (1982) Reliability of the relationship between hippocampal activity and sensory-behavioral events in the rat. Exp. Neurol. 75: 652-664.

Best, P. J., and L. T. Thompson (1984a) Hippocampal place cells show long-term stability of place field activity presented to the Second Conference on the Neurobiology of Learning and Memory, Irvine, CA.

Best, P. J., and L. T. Thompson (1984b) Hippocampal cells which have place field activity also show changes in activity during classical conditioning. Soc. Neurosci. Abstr. 10:125.

Buzsáki, G. (1986) Hippocampal sharp waves: Their origin and significance. Brain Res. 398: 242-252.

Buzsáki, G., L.-W. S. Leung, and C. H. Vanderwolf (1983) Cellular bases of hippocampal EEG in the behaving rat. Brain Res. Rev. 6 : 139-171.

Dykes, R., and Y. Lamour (1988) Neurons without demonstrable receptive fields outnumber neurons having receptive fields in samples 
from the somatosensory cortex of anesthetized or paralyzed cats and rats. Brain Res. 440: 133-143.

Feder, R., and J. B. Ranck, Jr. (1973) Studies on single neurons in the dorsal hippocampal formation and septum in unrestrained rats. II Hippocampal slow waves and theta cell firing during bar pressing and other behaviors. Exp. Neurol. 41: 532-555.

Foutz, A. S., E. Boudinot, M.-P. Morin-Surun, J. Champagnat, S. F. Gonsalvees, and M. Denavit-Saubié (1987) Excitability of "silent" respiratory neurons during sleep-waking states: An iontophoretic study in undrugged chronic cats. Brain Res. 404: 10-20.

Fox, S. E., and J. B. Ranck, Jr. (1975) Location and anatomical identification of theta and complex-spike cells in dorsal hippocampal formation of rats. Exp. Neurol. 49: 299-313.

Fox, S. E., and J. B. Ranck, Jr. (1981) Electrophysiological characteristics of hippocampal complex-spike cells and theta cells. Exp. Brain Res. 41: 399-410.

Hill, A. J., and P. J. Best (1981) Effects of deafness and blindness on the spatial correlates of hippocampal unit activity in the rat. Exp. Neurol. 74: 204-217.

Hubel, D. H., and T. N. Wiesel (1962) Receptive fields, binocular interaction and functional architecture in the cat's visual cortex. J. Physiol. (Lond.) 160: 106-154.

Hubel, D. H., and T. N. Wiesel (1977) Functional architecture of macaque monkey visual cortex. Proc. R. Soc. London [Biol.] 198: 1 59.

Kubie, J. L. (1984) A driveable bundle of microwires for collecting single-unit data from freely-moving rals. Physiol. Behav. 32: 115118 .

Kubie, J. L., and J. B. Ranck (1982) Tonic and phasic firing of rat hippocampal complex-spike cells in three different situations: Context and place. Adv. Behav. Biol. 26: 89-98.

Kubie, J. L., and J. B. Ranck (1983) Sensory-behavioral correlates in individual hippocampus neurones in three situations: Space and context. In Molecular, Cellular, and Behavioral Neurobiology of the Hippocampus, W. Seifert, ed., Academic, New York.

Kubie, J. L., L. Kramer, and R. U. Muller (1985a) Location-specific firing of hippocampal theta cells. Soc. Neurosci. Abstr. 11: 1231.

Kubie, J. L., R. U. Muller, and S. E. Fox (1985b) Firing fields of hippocampal place cells. In Electrical Activity of the Archicortex, G. Buzsáki and C. H. Vanderwolf, eds., Akademiai Kiado, Budapest.

Laurent, J. P., M. Mangold, U. Humbel, and W. Haefely (1983) Reduction by two benzodiazepines and pentobarbitone of the multiunit activity in substantia nigra, hippocampus, nucleus locus coeruleus, and nucleus Raphé dorsalis of encéphale isolé rats. Neuropharmacology 22: 501-511.

Leung, L.-W.S. (1984a) Pharmacology of the theta phase shift in the hippocampal region of freely moving rats. Electroencephalogr. Clin. Neurophysiol. 58: 457-466.

Leung, L.-W. S. (1984b) Model of gradual phase shift of theta rhythm in the rat. J. Neurophysiol. 52: 1051-1065.

Leung, L.-W. S., and C. H. Vanderwolf (1980) Behavior-dependent evoked potentials in the hippocampal CAl region of the rat. II. Effect of eserine, atropine, ether and pentobarbital. Brain Res. 198: 119133.

Leung, L.-W. S., and C. Y. Yim (1986) Intracellular records of theta rhythm in hippocampal CA1 cells of the rat. Brain Res. 367: 323327.

Mays, L. E., and P. J. Best (1973) Arousal from sleep, its effects on hippocampal neural activity. Sleep Res. 2: 34.

Mays, L. E., and P. J. Best (1975) Hippocampal unit activity to tonal stimuli during arousal from sleep and in awake rats. Exp. Neurol. 47: 268-279.
McNaughton, B. L., C. A. Barnes, and J. O'Keefe (1983) The contribution of position, direction, and velocity to single unit activity in the hippocampus of freely-moving rats. Exp. Brain Res. 52: 41-49.

McNaughton, N., J. Richardson, and C. Gore (1986) Reticular elicitation of hippocampal slow waves: Common effects of some anxiolytic drugs. Neuroscience 19: 899-903.

Miller, V. M., and P. J. Best (1980) Spatial correlates of hippocampal unit activity are altered by lesions of the fornix and entorhinal cortex. Brain Res. 194: 311-323.

Misgeld, U., and M. Frotscher (1986) Postsynaptic-GABAergic inhibition of non-pyramidal neurons in the guinea-pig hippocampus. Neuroscience 19: 193-206.

Muller, R. U., J. L. Kubie, and J. B. Ranck (1987) Spatial firing patterns of hippocampal complex-spike cells in a fixed environment. J. Neurosci. 7: 1935-1950.

O'Keefe, J. (1976) Place units in the hippocampus of the freely moving rat. Exp. Neurol. 51: 78-109.

O'Keefe, J. (1979) A review of the hippocampal place cells. Prog. Neurobiol. 13: 419-439.

O'Keefe, J., and D. H. Conway (1978) Hippocampal place units in the freely moving rat: Why they fire where they fire. Exp. Brain Res. 31: 573-590.

O'Keefe, J., and J. Dostrovsky (1971) The hippocampus as a spatial map. Preliminary evidence from unit activity in the freely-moving rat. Brain Res. 34: 171-175.

O'Keefe, J. and L. Nadel (1978) The Hippocampus as a Cognitive Map, Clarendon, Oxford.

Olmstead, C. E., and P. J. Best (1974) Effects of fimbria-fornix stimulation on hippocampal pyramidal cell responses. Soc. Neurosci. Abstr. 4: 140 .

Olmstead, C. E., P. J. Best, and L. E. Mays (1973) Neural activity in the dorsal hippocampus during paradoxical sleep, slow wave sleep, and waking. Brain Res. 60: 381-391.

Olton, D. S., and R. J. Samuelson (1976) Remembrance of places passed: Spatial memory in rats. J. Exp. Psychol.: Anim. Behav. Proc. 2: 97-116.

Olton, D. S., M. Branch, and P. J. Best (1978) Spatial correlates of hippocampal unit activity. Exp. Neurol. 58: 387-409.

Proctor, W. R., M. Mynlieff, and T. V. Dunwiddie (1986) Facilitatory action of etomidate and pentobarbital on recurrent inhibition in rat hippocampal pyramidal neurons. J. Neurosci. 6: 3161-3168.

Ranck, J. B., Jr. (1973) Studies on single neurons in the dorsal hippocampal formation and septum in unrestrained rats. I. Behavioral correlates and firing repetoires. Exp. Neurol. 41: 461-531.

Sinclair, B. R., M. G. Seto, and B. H. Bland (1982) Theta-cells in CA1 and dentate layers of hippocampal formation: Relations to slow-wave activity and motor behavior in the freely moving rabbit. J. Neurophysiol. 48: 1214-1225.

Suzuki, S. S., and G. K. Smith (1985) Single-cell activity and synchronous bursting in the rat hippocampus during waking behavior and sleep. Exp. Neurol. 89: 71-89.

Thompson, L. T., and P. J. Best (1986) Hippocampal place cells: Classifications, clarifications, and manipulations. Soc. Neurosci. Abstr. 12: 1211 .

Thompson, L. T., and P. J. Best (1988) Hippocampal place cell to silent cell ratios in freely-behaving rats. Soc. Neurosci. Abstr. 14: 126.

Thompson, L. T., J. Kapur, P. N. Lacey, R. A. Salerno, and P. J. Best (1985) Silent hippocampal pyramidal cells in awake freely-behaving rats. Soc. Neurosci. Abstr. 11: 1232. 